\title{
Meeting a National Emission Reduction Target in an Experimental Setting
}

\section{Kerri Brick* and Martine Visser}

September 2010

Draft, do not cite

\begin{abstract}
Climate change poses the ultimate dichotomy between social welfare and individual incentives because, despite the global benefits synonymous with mitigation, individuals lack incentive to reduce their own emissions. Using a public good experiment with a climate change framing, this paper examines the scope for cooperation in meeting a national mitigation goal; in particular, the experimental design examines how different sectors with differing marginal abatement costs distribute the responsibility of reducing emissions between themselves. The experiment consists of four treatments including the counterfactual baseline scenario which examines voluntary cooperation, a communication treatment examining the role of stakeholder participation in facilitating cooperation and, finally, two treatments simulating a carbon tax, where the carbon tax reflects an electricity levy. The results suggest that voluntary cooperation will not be sufficient to meet the mitigation target. While communication significantly increases average contribution levels, it also polarises individual player strategies between full cooperation and free riding. With the introduction of a tax, cooperation becomes near-universal. However, a carbon tax crowds out contributions in excess of a specified mitigation target. This emphasises the important of choosing the correct tax level.
\end{abstract}

Keywords: climate change, national target, public good, communication, taxation

*Environmental Policy Research Unit, University of Cape Town; email: kerri.brick@uct.ac.za 


\section{Introduction}

Given mitigation as a public good, climate change poses the ultimate social dilemma: curtailing greenhouse gas emissions entails a private cost while the benefits are shared equally by all - creating an incentive for individuals to free-ride, ultimately emitting more greenhouse gases than is optimal (Brekke and Johansson-Stenman 2008).

While the dominant strategy in linear public good games is for each player to contribute nothing, subjects make positive but suboptimal contributions to public good provision (Cherry and Kroll 2005). Similarly, in the application to mitigation, despite no individual incentive to do so, governments, businesses and individuals are taking steps to reduce emissions. As Irwin (2009) notes, this attempt at reducing emissions does not imply that emission levels will be reduced to optimal levels, but suggests that potential for cooperation exists. Using a public good framework with a climate change framing, this paper explores the potential for cooperation in the context of this social dilemma.

A variant of the standard Voluntary Contribution Mechanism (VCM) is used to examine the cooperative behaviour of different player-types in meeting a national emission reduction target when players can invest in mitigation or continue with business-as-usual. The two player-types, who represent different sectors of society, have differing marginal costs of abatement. The experiment consists of four treatments: the standard VCM, a VCM with communication opportunities and two VCM variants which specify minimum contributions to the public good. The experiment is carried out with university students in South Africa. The South African context is of particular interest given that the country is the largest emitter in Africa and is committed to reducing emissions by $34 \%$ below business as usual by 2020 (conditional on an equitable outcome in global climate talks). 
The significant reduction in greenhouse gases needed to avoid catastrophic climate change requires a great degree of cooperation among asymmetric agents. The Kyoto Protocol requires countries with large income and historical emission disparities to reach consensus on individual targets for the reduction of emissions. On a national scale, reducing a national greenhouse inventory requires a change of behaviour from industry and individuals who are asymmetric with regards to income, energy consumption, abatement costs and historical emissions. Whereas the experimental evidence from public good games with homogenous groups reflect the norm of equal contributions (Fehr and Fischbacher 2004, Reuben and Riedl 2009, Gächter and Herrmann 2009), it is not immediately evident what contribution norm will arise in a public good context with heterogeneous groups. Experimental evidence of the effect of asymmetry on cooperation is mixed. ${ }^{1}$ Some authors report that heterogeneity improves group contribution levels (Chan et al. 1999, Chan et al. 1996), while others find the opposite effect (Anderson et al. 2004, Rappoport and Suleiman 1993, Cherry et al. 2005, Isaac and Walker 1988).Fisher et al. (1995), who examine the impact of asymmetric MPCRs in a linear public good setting, find that low-MPCR players contribute less to public good provision relative to high-MPCR players. In terms of the impact of endowment heterogeneity on individual contributions, Buckley and Croson (2006) report that low income players contribute a higher proportion of income to the public account relative to high income players and Hofmeyr et al. (2007) conclude that wealthy players contribute the same percent of income to the public account as their wealthier counterparts. The impact of heterogeneity on cooperation is particularly significant in the context of mitigation given that suboptimal levels of cooperation will not subvert the potentially catastrophic effects of climate change.

\footnotetext{
${ }^{1}$ Asymmetry has been introduced into the public good framework by varying subjects' participation fees (Anderson et al. 2004), endowments (Rappoport and Suleiman 1993, Bagnoli and McKee 1991, Cherry et al. 2005, Chan et al. 1996, Buckley and Croson 2006, Hofmeyr et al. 2007, Isaac and Walker 1988, Chan et al. 1999), marginal per capital returns (MPCRs) (Fisher et al. 1995, Tan 2008) and private account valuations (Palfrey and Prisbrey 1997).
} 
The experimental results suggest that voluntary contributions are insufficient to meet a mitigation goal. Specifically, in the baseline treatment, the most dominant contribution norm, irrespective of player-type, was to free ride. With the introduction of communication, average contribution increased: the number of groups meeting the mitigation target increased from $35 \%$ to $50 \%$. However, communication increased the polarisation of player strategies between free riding and full cooperation. Despite this fact, the frequency of full cooperation increased significantly with the introduction of communication suggesting that communication helps "high cooperators" to coordinate strategies (Gächter and Herrmann 2009). The results suggest that stakeholder participation plays an important role in a national climate dialogue. Taxation resulted in near universal compliance with the target. Importantly, taxation may crowd out contributions in excess of the target. This makes choosing the right tax level critical for the environmental result.

The paper proceeds as follows: Section 2 describes the policy setting and problems which underpin the experiment design. Section 3 describes the experimental framing, design and parameters. The experimental results are examined in Section 4. Section 5 draws policy implications.

\section{$2 \quad$ Policy setting}

A public good experiment is used to examine the cooperative behaviour of different playertypes in reducing a national greenhouse gas inventory - when players can invest in either mitigation or continue with business-as-usual.

The experimental design analyses a particular dimension of the carbon pricing question, namely, how players with differing marginal costs of abatement distribute the responsibility of reducing emissions between themselves. While the scenario is applicable to any context in which marginal abatement costs differ, the framing specifically refers to "capital" and 
"labour". Players were explicitly told to think of capital as representing firms and labour as representing households.

In line with the climate change framing, players are told that government has specified a national emission reduction target; only in some instances is the target binding. The experiment includes four treatments. To construct a proper counterfactual, the status quo treatment examines the potential for voluntary cooperation in meeting a mitigation target. This treatment is extended in the following round by allowing players to communicate with one another. The communication treatment is assessing the importance of stakeholder participation in promoting cooperation (by facilitating buy-in and creating a shared sensed of responsibility). The final two treatments simulate a carbon tax. Treasury unequivocally favours a carbon tax, noting in the 2010 Budget Review that the electricity levy introduced in 2008 is the first step towards a carbon tax in South Africa (National Treasury, 2010). Given that the electricity sector accounts for nearly $50 \%$ of South Africa's emissions (Winkler and Marquard 2009) and the fact that South Africa is contending with critically low reserve margins, the design of the carbon tax reflects both demand side management (DSM) and emission mitigation objectives in the electricity sector. As such, the carbon tax schemes are designed to simulate electricity levies and, specifically, a uniform and a differential tax on peak electricity consumption. These differential tax schemes emphasize the equity and distributive fairness considerations that have become important subtexts in global and national climate change negotiations. We assume it is cheaper for firms to reduce a given unit of peak electricity consumption, relative to households, given greater mitigation opportunities (low hanging fruit) and the ability to take advantage of off-peak rates. 


\section{Experiment}

Upon entering the lab, participants were told to think of themselves as representing either capital (firms) or labour (households). The game was played in groups of four consisting of two capital and two labour players.

In the standard VCM (baseline treatment), participants are endowed with 10 tokens, and must decide how to allocate the tokens between a private and public account, where the public account signifies investments in mitigation.

Subjects' payoffs are given by Equations 1 and 2, where $c_{K_{i}}$ and $c_{L_{i}}$ signify investments in the public good by capital and labour, respectively.

The private account represents investment opportunities other than investing in mitigation. Because capital can more easily invest in productive (income-generating) activities as compared to labour, capital earns a higher return from money invested in the private account. Equations 1 and 2 indicate that each token contributed to the private account generates a private return of 12 and 6 tokens for capital and labour, respectively.

$$
\begin{aligned}
& \pi_{K_{i}}=12\left(10-c_{K_{i}}\right)+0.25\left(20 \times \sum_{i=1}^{2} c_{K_{i}}+10 \times \sum_{i=1}^{2} c_{L_{i}}\right) \\
& \pi_{L_{i}}=6\left(10-c_{L_{i}}\right)+0.25\left(20 \times \sum_{i=1}^{2} c_{K_{i}}+10 \times \sum_{i=1}^{2} c_{L_{i}}\right)
\end{aligned}
$$

It is assumed that marginal contributions to the public account are asymmetric. Households have limited avenues with which to achieve significant reductions in electricity consumption; specifically, households can purchase solar water heaters, geyser blankets, replace incandescent light bulbs with more efficient Compact Fluorescent Light bulbs 
(CFLs), and reduce heating requirements by improving insulation. While expensive for the average household, many of these measures are prohibitively expensive for low-income households. Conversely, in addition to the above measures, the commercial sector can take advantage of "low hanging fruit" (decommission lifts and revolving doors, use timers to switch off lights in buildings and parking lots etc.). It is therefore assumed that capital has a lower marginal cost of abatement relative to labour, and is able to reduce more emissions with one token. In other words, each token invested by capital in mitigation makes a larger marginal contribution to the public good relative to a token invested by labour. Capital and labour's contributions to the public account are therefore multiplied by 20 and 10 , respectively, reflecting the idea that capital is able to contribute more to emissions reductions relative to labour, at the same personal cost. This is illustrated in Table 1, which tabulates emissions reductions, per token invested in the public account, for both player types. Note that the sum of contributions to the public account denotes the units of emissions reduced by the group.

[Insert Table 1 here]

The tokens invested in mitigation are distributed equally amongst the four group members: no one is excluded from the benefits of mitigation. Thus, each member of the group receives the same income from the public account - irrespective of his or her contribution level. As such, one token invested in the public account by capital generates a return for each group member of 5 tokens; similarly, one token invested in the public account by labour generates a return for each group member of 2.5 tokens. Notably, for both capital and labour, the marginal per capita return (MPCR), which is the ratio between the marginal value of a token invested in mitigation and the marginal value of a token invested in the private account, is 0.42. Thus the MPCR from investing in mitigation is the same for all players, again indicating that players derive the same benefit from mitigation. 
As the setting of the national target forms part of a multilateral commitment to reduce emissions, the return from mitigation quantifies the benefit of a decrease in the risks related to climate change, such as environmental disaster. ${ }^{2}$ In addition, with a focus on DSM in the electricity sector, the returns from mitigation include a reduction in the probability of blackouts amid reduced peak consumption.

Given that the return to mitigation for each player is less than the return from the private account, the dominant strategy for both capital and labour is to invest nothing in mitigation whereas the social optimum is achieved when all players contribute their full endowment to mitigation.

Subjects were told that government has set a national emission reduction target in line with its multilateral obligations. An explicit reduction target of 240 units was specified. Table 1 illustrates that the target can be met via capital and labour contributing different combinations of tokens to the public good. In this first treatment, the target was not binding but government's commitment in meeting the target was emphasised.

This VCM is extended by way of three experimental variants which are outlined below:

Variant 1. Introduce the possibility of communication with group members.

The communication treatment is identical to the baseline treatment except that subjects were able to communicate with their group members via an online chat program in order to decide, as a group, how best to meet the target. Players were informed that the group decision was not binding and that they were still free to decide on their own contribution. In their review of the experimental evidence, Gächter and Herrmann (2009) argue that communication facilitates and sustains cooperation. They note that communication helps

\footnotetext{
${ }^{2}$ We add the caveat that the benefits of avoided climate impacts would only be realised in the event that other countries similarly cooperated.
} 
cooperators to coordinate strategies, adds a dimension of social pressure and introduces feelings of guilt when mutual promises are broken. In an application to climate policy, Irwin (2009) discusses the use of communication as an avenue to promote a cooperative norm through moralizing, while Gowdy (2007) argues that creating a shared responsibility and appealing to a sense of common good is an effective way to garner support for environmental policies.

Variant 2. Specify minimum contributions to the public good and sanction free-riding; equal emission reductions.

All sectors in the economy reduce emissions equally, irrespective of the difference in the cost of abatement. To meet the target of reducing emissions by 240 units and reduce emissions by the same quantity, all four players must reduce emissions by 60 units each. This is equivalent to each capital player contributing 3 tokens to the public account and each labour player contributing 6 tokens (Table 1) (this treatment is referred to as Tax36). Each player is fined ten tokens for every token below the specified minimum contribution.

A policy parallel is a uniform tax on peak consumption. In addition to having a lower marginal cost of abatement, firms would be better able, relative to households who have fixed energy requirements - for example cooking dinner and washing clothing after work at peak times, to take advantage of off-peak rates.

Subjects' payoffs are given by:

$$
\begin{aligned}
& \pi_{K_{i}}=12\left(10-c_{K_{i}}\right)+0.25\left(20 \times \sum_{i=1}^{2} c_{K_{i}}+10 \times \sum_{i=1}^{2} c_{L_{i}}\right) \text { if } c_{K_{i}} \geq 3 \\
& \pi_{K_{i}}=12\left(10-c_{K_{i}}\right)+0.25\left(20 \times \sum_{i=1}^{2} c_{K_{i}}+10 \times \sum_{i=1}^{2} c_{L_{i}}\right)-\left(10 \times\left(3-c_{K_{i}}\right)\right) \text { if } c_{K_{i}}<3
\end{aligned}
$$




$$
\begin{aligned}
& \pi_{L_{i}}=6\left(10-c_{L_{i}}\right)+0.25\left(20 \times \sum_{i=1}^{2} c_{K_{i}}+10 \times \sum_{i=1}^{2} c_{L_{i}}\right) \text { if } c_{L_{i}} \geq 6 \\
& \pi_{L_{i}}=6\left(10-c_{L_{i}}\right)+0.25\left(20 \times \sum_{i=1}^{2} c_{K_{i}}+10 \times \sum_{i=1}^{2} c_{L_{i}}\right)-\left(10 \times\left(6-c_{K_{i}}\right)\right) \text { if } c_{L_{i}}<6
\end{aligned}
$$

The Nash Equilibrium is moved inwards to $(3,6)$ for (capital, labour), respectively.

Variant 3. Specify minimum contributions to the public good and sanction free-riding; the cost of reducing emissions is split equally between player-types.

Capital and Labour can reduce emissions by different quantities as long as they are contributing the same amount in tokens. If each capital and labour player contributes 4 tokens, each group will collectively meet the emission reduction target (see Table 1) (this treatment is referred to as Tax44). In this case, capital players must reduce emissions by 80 units each, while labour players must reduce emissions by 40 units each. Each player is fined ten tokens for every token below the specified minimum contribution. The analogous policy example in this case would be differential rates on peak consumption (progressive tax). Subjects' payoffs are given below.

$$
\begin{aligned}
& \pi_{K_{i}}=12\left(10-c_{K_{i}}\right)+0.25\left(20 \times \sum_{i=1}^{2} c_{K_{i}}+10 \times \sum_{i=1}^{2} c_{L_{i}}\right) \text { if } c_{K_{i}} \geq 4 \\
& \pi_{K_{i}}=12\left(10-c_{K_{i}}\right)+0.25\left(20 \times \sum_{i=1}^{2} c_{K_{i}}+10 \times \sum_{i=1}^{2} c_{L_{i}}\right)-\left(10 \times\left(4-c_{K_{i}}\right)\right) \text { if } c_{K_{i}}<4 \\
& \pi_{L_{i}}=6\left(10-c_{L_{i}}\right)+0.25\left(20 \times \sum_{i=1}^{2} c_{K_{i}}+10 \times \sum_{i=1}^{2} c_{L_{i}}\right) \text { if } c_{L_{i}} \geq 4 \\
& \pi_{L_{i}}=6\left(10-c_{L_{i}}\right)+0.25\left(20 \times \sum_{i=1}^{2} c_{K_{i}}+10 \times \sum_{i=1}^{2} c_{L_{i}}\right)-\left(10 \times\left(4-c_{K_{i}}\right)\right) \text { if } c_{L_{i}}<4
\end{aligned}
$$


The Nash Equilibrium is moved inwards to $(4,4)$ for (capital, labour), respectively.

\subsection{Procedures}

The experiment was conducted with 204 students recruited from the University of Cape Town (UCT) in the Western Cape of South Africa. Students from a broad spectrum of faculties were targeted for participation including commerce, humanities and the built environment.

The experiment consisted of three different sequences. Sequence 1 merely consisted of four repetitions of the baseline treatment and acts as a control: Seq $1\left(B_{1}, B_{2}, B_{3}, B_{4}\right)$. Sequence 2 and 3 consisted of the baseline, communication and tax treatments, and differed only in the ordering of the treatments: Seq $2\left(\mathrm{~B}_{1}\right.$, Comm., Tax ${ }_{36}$, Tax $\left.{ }_{44}\right)$; Seq $3\left(\mathrm{~B}_{1}\right.$, Tax ${ }_{44}$, Comm., $\operatorname{Tax}_{36}$ ). All experimental sessions commenced with Baseline ${ }_{1}$ as it was important that subjects understand the experiment framing. Each sequence was completed over 2 sittings and consisted of a sample of 68 subjects.

The experiments were performed manually. Upon entering the laboratory, each participant randomly drew an experiment number and factor of production. Unless told otherwise, communication was prohibited with anyone except the experimenter. Subjects were aware that each group consisted of two capital and two labour players, but were not aware of the identities of their group members. Information relating to their group members' individual contributions was also not made available. Participants were assigned to new groups at the start of each treatment.

The instructions were read aloud by the experimenter while the subjects followed on their own hard copies. Payoffs were common knowledge. While the experiment had a climate 
change framing, the instructions were neutrally-worded in relation to issues around social justice. In addition, language referring to capital and labour remained neutral: subjects were simply told to think of capital as representing firms and labour as representing households.

Apart from the instructions, students were provided with summary sheets and payoff tables to assist them in making their decisions. Before commencing with the experiment, examples were conducted with the participants. In addition, an excel-spreadsheet calculator was provided to students for use during the experiment.

Mann-Whitney tests can't reject the null hypothesis that the contributions in the two sittings of each sequence are drawn from the same distribution ( $p>0.110$ for all sequences) (See Appendix A). As such, when discussing the experimental results for each treatment, mean contributions are averaged across the two sittings in which each sequence was conducted. In addition, like-treatments in Sequence 2 and 3 will be pooled given that Mann-Whitney tests do not find them to be significantly different (Appendix A).

\section{Experimental results}

This section provides an analysis of the experimental results. The main policy conclusions are drawn in the discussion in Section 5.

Average earnings for participating in the experiment (including the R20 show-up fee) were approximately R132. Capital players fared better at R152 while Labour players averaged R111.

\subsection{Contribution levels and norms}

Table 2 reflects the average contributions of players across the various treatments. 


\subsubsection{Baseline (Sequence 1)}

As reflected in Table 2, average contribution levels (across player-types) range between 2.2 - 2.9 for the 4 treatments in Sequence 1 (Baseline). These contribution rates undershoot those typically seen in the literature, where, in one shot public good games, contributions to the public good generally range between $40-60 \%$ of endowments (Ledyard 1995). Contribution levels are more in line with those seen in repeated play, where contributions decay over time (Hermann et al. 2008) but remain between $15-25 \%$ of individual endowments in the final round (Isaac and Walker 1988). While the Spearman rank-order correlation between mean contributions and treatments is negative but insignificant ( $\rho=-0.0073, p>0.100)$ over all four treatments, the decreasing pattern for the first three treatments is significant at the $10 \%$ level $(\rho=-0.121, p>0.084)$.

[Insert Table 2 here]

Observation 1. Player heterogeneity has no significant impact on cooperation

Figure 1 plots the average contributions of both player-types in each of the 4 treatments in Sequence 1 (Baseline). Mann-Whitney tests confirm there to be no significant difference between capital and labour contributions in each treatment ( $p>0.080$ for all four treatments). Appendix B illustrates the distribution of capital and labour contributions, by treatment. Over the 4 treatments, capital contributes zero tokens $37 \%$ of the time as compared to $40 \%$ for labour. The most apparent contribution norm, irrespective of player-type, is to contribute zero tokens (free-ride).

[Insert Figure 1 here] 


\subsubsection{Communication (Sequence 2 and 3)}

Observation 2. Communication significantly increases cooperation

Average contributions across player-types increased from 3.2 in the baseline treatment to 4.4 with communication (Table 2). Capital increased contributions on average by 1.4 tokens; this is comparably similar to that of labour where contributions increased by an average 1.1 tokens. Wilcoxon signed-rank tests confirm that communication significantly increases average contributions (average: $p=0.001$; capital: $p=0.018$; labour: $p=0.034$ ). A Mann-Whitney test indicates there to be no significant difference between capital and labour average contributions $(p<0.001)$ in the presence of communication.

An examination of individual (as opposed to mean) contribution rates confirms that communication significantly increases cooperation. Table 3 reflects the frequency of contributions at each possible contribution level for the Baseline and Communication treatments, by player-type. It is evident that communication increases the frequency of plays of ten tokens (full-cooperation) and zero tokens (free-riding). A plot of the frequency distributions in Appendix $\mathrm{C}$ confirms that communication polarises contribution levels at 0 and 10 tokens.

For capital, a comparison of the frequency of plays of 10 tokens between the Baseline and Communication treatments is significant at the $1 \%$ level $^{3}$ confirming that communication encourages cooperative behaviour. Conversely, a comparison of the frequency of plays of zero tokens between the two treatments is insignificant $\left(\chi_{[1]}^{2}=0.654, p=0.419\right)$.

[Insert Table 3 here]

\footnotetext{
${ }^{3}$ Fisher exact test: frequency of plays of ten tokens in the baseline treatment $<5$.
} 
For labour, a comparison of the frequency of plays of 10 tokens between the Baseline and Communication treatments is highly significant $(p<0.01)^{4}$, while a comparison of the frequency of plays of zero tokens between the two treatments is insignificant $\left(\chi_{[1]}^{2}=1.966, p=0.161\right)$. Once again, communication encourages cooperative behaviour.

Observation 3. Labour free-rides significantly more than capital

Do contributions of zero and ten tokens differ by player-type? The frequency of plays of zero tokens in the baseline treatment is $21 \%$ for capital as compared to $34 \%$ for labour. This difference is only significant at the $10 \%$ level $\left(\chi_{[1]}^{2}=3.007, p=0.083\right)$. In the communication treatment, capital contributes zero $27 \%$ of the time versus $46 \%$ for labour. Thus, with communication, labour free-rides significantly more than capital $\left(\chi_{[1]}^{2}=5.392, p=0.020\right)$

This result suggests that subjects with a higher marginal cost of abatement/lower marginal contribution to the public good under-contribute to the public good relative to their counterparts with a lower marginal cost, unless they are forced to contribute through a tax regime.

\subsubsection{Taxation}

The emission reduction target of 240 can be met through capital and labour players contributing different combinations of tokens towards public good provision (Table 1). In the context of a homogonous group-setting, where equal contributions to the public good would imply equal emissions reductions and earnings, a reasonable contribution norm would dictate that all players contribute the same amount in tokens (Ruben and Riedl 2009),

\footnotetext{
${ }^{4}$ Fisher exact test: frequency of plays of ten tokens in the baseline treatment $<5$.
} 
however, in the context of heterogeneous groups such as ours, it is not clear what allocation principle should apply.

Observation 4. Taxation reduces the frequency of contributions below the specified contribution rate

In the baseline treatment, the Nash equilibrium was $(0,0)$ for both capital and labour players. In the case of the Tax36 and Tax44 treatment, the Nash is moved inwards to $(3,6)$ and $(4,4)$ for capital and labour, respectively. ${ }^{5}$ As evident from Table 2, average contributions for both players approximate (or exceed) the Nash, as expected. ${ }^{6}$ In the Tax36 treatment, $65 \%$ of capital players contribute 3 tokens while $74 \%$ of labour players contribute 6 tokens. Similarly, in the Tax44 treatment, $56 \%$ of capital and labour players contribute 4 tokens. Chi-square tests confirm that in the tax treatments, as compared to the baseline and communication treatments, the frequency of contributions below the specified minimum contributions is reduced. This suggests that taxation discourages contributions below the minimum contribution. These results serve to confirm that subjects fully understood the payoffs associated with the experiment.

Observation 5. Taxation crowds-out ${ }^{7}$ contributions in excess of the Nash equilibrium for capital players

\footnotetext{
${ }^{5}$ The Nash equilibrium become $(3,6)$ and $(4,4)$ in the Tax36 and Tax44 treatments, respectively, as capital and labour can never do better than contributing their corresponding amounts since contributing less when faced with a tax will result in losses.

${ }^{6}$ Contributions increase significantly in the Tax36 treatment (Wilcoxon signed-rank test: $p<0.01$ ) and Tax44 treatment (Wilcoxon signed-rank test: $p<0.01$ ) relative to the baseline.

${ }^{7}$ A pre-requisite for complete crowding-out is that the pre and post-taxation Nash equilibrium is an interior solution (Andreoni, 1993). As we are testing for the frequency of free-riding, in our design, the Nash equilibrium before taxation is for each subject to contribute zero to the public good. Thus, we simply comment on the degree to which rising taxes partially crowd out voluntary contributions.
} 
While the presence of taxation certainly reduces free-riding, it is necessary to examine whether the introduction of a tax reduces the likelihood of subjects contributing in excess of the minimum contribution.

Capital contributed 4 or more tokens $31 \%$ of the time in the Tax36 treatment as compared to $44 \%$ in the baseline treatment $\left(\chi_{[1]}^{2}=5.128, p<0.05\right)$ and $54 \%$ in the communication treatment $\left(\chi_{[1]}^{2}=7.696, p<0.01\right)($ Table 3$)$; the fact that these differences are highly significant indicates that the presence of the tax discourages cooperative behaviour beyond the specified target. Capital plays 5 or more tokens $31 \%$ of the time in the Tax44 treatment as compared to $28 \%$ in the baseline treatment and $47 \%$ in the communication treatment $\left(\chi_{[1]}^{2}=3.741, p=0.053\right)$; the introduction of the tax discouraged cooperative behaviour relative to the communication treatment.

In the Tax36 treatment, labour contributes 7 or more tokens $25 \%$ of the time, as compared to $10 \%$ for the baseline treatment and $37 \%$ for the communication treatment. Comparison of the tax treatment with the baseline treatment yields a statistically significant result $\left(\chi_{[1]}^{2}=5.396, p<0.05\right)$, while comparison with communication is only significant at the $15 \%$ level. Relative to the baseline treatment, the presence of a tax encourages cooperative behaviour. Finally, labour contributes 5 or more tokens $44 \%$ of the time in the Tax44 treatment, versus $31 \%$ in the baseline case and $44 \%$ in the presence of communication. A comparison between the tax and baseline frequencies is significant at the $11 \%$ level $\left(\chi_{[1]}^{2}=2.541\right)$

The effect of the tax thus differs according to player-type. Taxation discourages contributions in excess of the Nash equilibrium for capital as compared to the baseline and 
communication scenarios. Conversely, in the case of labour, taxation encourages cooperative behaviour beyond the Nash equilibrium.

The impact of the different tax schedules on contributions is tested more formally by performing a pooled OLS regression using the pooled data from the baseline and tax treatments in Sequence 2 and 3. The regression is run separately for capital and labour. Following Benzing and Andrews (2004) the model is specified as:

$H=\alpha+\beta_{1} D_{1}+\beta_{2} D_{2}+\varepsilon$

where $H$ signifies the contribution in excess of the specified tax rate.

Note: this analysis differs slightly from above as the baseline treatment is treated as an example of a tax of zero. Thus, the constant term, $\alpha$, signifies (voluntary) average contributions amid a tax of zero (any contribution greater or equal to one is voluntary). For capital, $D_{1}=1$ if the tax is 4 and 0 otherwise (Tax44), while $D_{2}=1$ if the tax is 3 and 0 otherwise (Tax36 treatment). For labour, $D_{1}=1$ if the tax is 4 and 0 otherwise (Tax44), while $D_{2}=1$ if the tax is 6 and 0 otherwise (Tax36). The results from the regression are replicated in Table 4 . The expected values of $H$ for the different tax specifications are reported in Table 5. The results indicate that the voluntary contribution levels decline as the burden of the tax rises, suggesting there is incomplete crowding out (Andreoni, 1993).

\subsection{Public good provision}

Observation 6. Communication and taxation increase compliance with the target

Table 6 reflects the percentage of groups that met the target across the various treatments. In sequence 1 , on average across the 4 treatments, $18 \%$ of groups met the target. With respect to the pooled data (Sequence 2 and 3), 35\% of groups in the baseline treatment met the 
target. With the introduction of communication, $50 \%$ of groups met the target. Compliance with the target increases markedly with the introduction of taxation.

\section{Discussion}

The baseline treatment examines voluntary cooperation in the context of meeting a mitigation goal. The baseline treatments in Sequence 1 suggest that cooperation decays over time. Furthermore, it was found that the most apparent contribution norm, irrespective of player-type, is to contribute zero tokens (free-ride). The predilection towards free-riding is explained by the high opportunity cost associated with investing in mitigation. For capital, 1 token invested in the private account returns 12 tokens, outpacing the public account return of 5. Likewise, for labour, the private account return of 5 exceeds the return of 2.5 from investing in the environment. As such, the individual return to mitigation, for both playertypes, is less than the return earned on alternate investment opportunities.

The communication treatment is identical to the baseline treatment except that subjects were able to communicate with their group members via an online chat program in order to decide, as a group, how best to meet the target; however, the group decision was not binding. Average contributions increased with communication. Furthermore, the frequency of individual plays of ten tokens in the communication treatment relative to the baseline treatment increased significantly - indicating that communication facilitated cooperation by helping high cooperators to coordinate strategies (Gächter and Herrmann 2009). The results suggest that stakeholder participation plays an important role in a national climate dialogue. However, the experimental results suggest that communication polarises player strategies. Around $26 \%$ and $31 \%$ of capital players contributed either zero or ten tokens in the communication treatment, respectively. In the case of labour, $46 \%$ contributed zero tokens while $25 \%$ contributed ten tokens. This result indicates that the introduction of punishment 
for free-riders would facilitate further cooperation. The inclusion of a punishment round is a natural extension to this experimental framing. In the context of compliance with a national emissions reduction target, the results indicate that voluntary cooperation may not be sufficient to reach a national target. In the Baseline treatment, only $35 \%$ of groups met the target. With the introduction of communication, cooperation is significantly improved: $50 \%$ percent of groups reach the target. While an improvement, in the context of climate change, $50 \%$ compliance would not be sufficient to subvert catastrophic climate change.

Two carbon tax regimes were simulated, namely equal reduction in emissions (uniform tax on peak consumption) and equal cost of reducing emissions (differential rates on peak consumption). Taxation results in near universal compliance with the target. However, the results also indicate that a carbon tax may crowd out contributions in excess of a given mitigation goal. For capital, the tax decreases the frequency of contributions in excess of the tax relative to the communication treatment. This is also true of labour in the uniform tax scheme. This makes choosing the right tax level critical for the environmental result.

It is also evident that taxation has an opposite effect on voluntary cooperation in the two groups "capital" and "labour". For labour, taxation encourages contributions in excess of the tax relative to the baseline treatment. The analysis of the baseline and communication treatments (sequence 2 and 3 ) indicate that labour free-rides significantly more than capital where capital and labour are two groups with different marginal abatement cost curves. This result might well be due to the equity subtext of the framing: mitigation by capital (who has a relatively lower marginal cost of abatement) is more efficient per token. By reducing inequity (particularly in the case of differential tax on peak consumption), taxation encourages voluntary cooperation in excess of the mitigation target from labour. 
Table 1. Emissions reductions, per token invested in the public account

\begin{tabular}{ccc}
\hline Tokens & \multicolumn{2}{c}{$\begin{array}{c}\text { Units emissions } \\
\text { reduced }\end{array}$} \\
\hline & $\mathbf{K}$ & $\mathbf{L}$ \\
0 & 0 & 0 \\
1 & 20 & 10 \\
2 & 40 & 20 \\
3 & 60 & 30 \\
4 & 80 & 40 \\
5 & 100 & 50 \\
6 & 120 & 60 \\
7 & 140 & 70 \\
8 & 160 & 80 \\
9 & 180 & 90 \\
10 & 200 & 100 \\
\hline
\end{tabular}

Table 2. Average contributions

\begin{tabular}{lccc|lccc}
\hline \multicolumn{5}{c}{ Sequence 1 } & \multicolumn{4}{c}{ Sequence 2 and 3 } \\
\hline & Avg. & $\mathrm{K}$ & $\mathrm{L}$ & & Avg. & $\mathrm{K}$. & $\mathrm{L}$ \\
Baseline $_{1}$ & 2.9 & 2.7 & 3.1 & Baseline $_{1}$ & 3.2 & 3.4 & 3.0 \\
Baseline $_{2}$ & 2.3 & 1.8 & 2.9 & Comm. $_{1}$ & 4.4 & 4.8 & 4.1 \\
Baseline $_{3}$ & 2.2 & 2.3 & 2.1 & Tax $_{36}$ & 5.3 & 3.9 & 6.6 \\
Baseline $_{4}$ & 2.4 & 2.4 & 2.3 & Tax $_{44}$ & 4.7 & 4.4 & 5.0 \\
\hline
\end{tabular}


Figure 1. Average contribution to public account

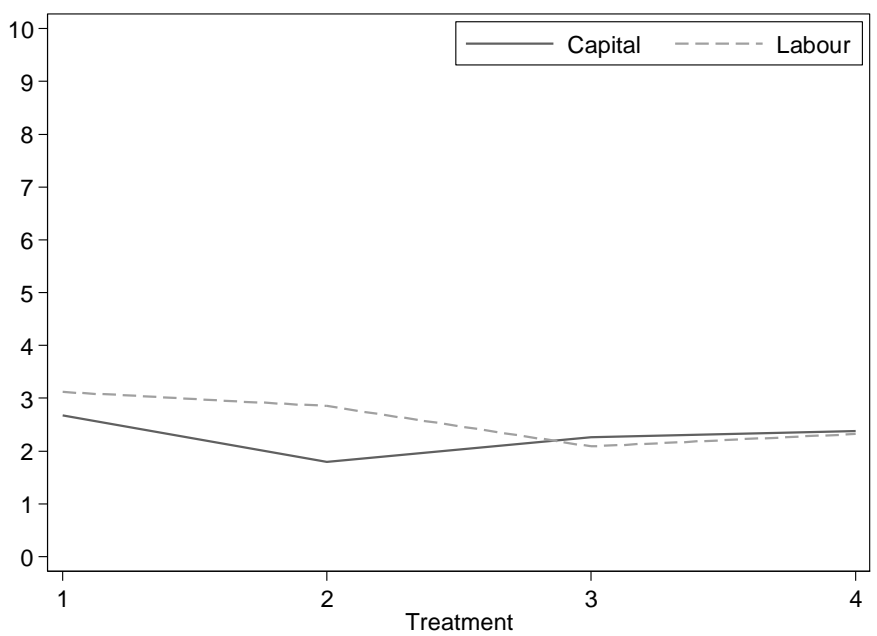

Table 3. Frequency distribution of contributions to the public good, by treatment and

$$
\text { player-type }
$$

\begin{tabular}{|c|c|c|c|c|c|c|c|c|c|c|c|}
\hline \multirow[t]{2}{*}{ Treatment } & \multicolumn{11}{|c|}{ Contribution } \\
\hline & 0 & 1 & 2 & 3 & 4 & 5 & 6 & 7 & 8 & 9 & 10 \\
\hline \multicolumn{12}{|l|}{ Capital $(n=68)$} \\
\hline Baseline & 0.206 & 0.103 & 0.059 & 0.191 & 0.162 & 0.074 & 0.059 & 0.029 & 0.059 & 0.000 & 0.059 \\
\hline Communication & 0.265 & 0.044 & 0.074 & 0.074 & 0.074 & 0.088 & 0.029 & 0.029 & 0.015 & 0.000 & 0.309 \\
\hline Tax36 & 0.015 & 0.000 & 0.029 & 0.647 & 0.074 & 0.059 & 0.074 & 0.029 & 0.015 & 0.000 & 0.059 \\
\hline Tax44 & 0.044 & 0.015 & 0.000 & 0.074 & 0.559 & 0.132 & 0.103 & 0.029 & 0.000 & 0.000 & 0.044 \\
\hline \multicolumn{12}{|l|}{ Labour $(n=68)$} \\
\hline Baseline & 0.338 & 0.074 & 0.088 & 0.059 & 0.132 & 0.132 & 0.074 & 0.015 & 0.029 & 0.000 & 0.059 \\
\hline Communication & 0.456 & 0.029 & 0.029 & 0.000 & 0.044 & 0.029 & 0.044 & 0.029 & 0.044 & 0.044 & 0.250 \\
\hline Tax36 & 0.015 & 0.000 & 0.000 & 0.000 & 0.000 & 0.000 & 0.735 & 0.074 & 0.059 & 0.015 & 0.103 \\
\hline Tax44 & 0.000 & 0.000 & 0.000 & 0.000 & 0.559 & 0.250 & 0.044 & 0.044 & 0.015 & 0.015 & 0.074 \\
\hline
\end{tabular}


Table 4. Estimates of crowding-out

\begin{tabular}{l|cc|cc}
\hline $\begin{array}{l}\text { Dep var: } H \\
\text { = vol. contr }\end{array}$ & \multicolumn{2}{|c|}{ Capital } & \multicolumn{2}{c}{ Labour } \\
\hline & Value & S.E. & Value & S.E. \\
$\alpha$ & $3.426^{*}$ & 0.346 & $2.985^{*}$ & 0.360 \\
$\beta_{1}$ & $-2.735^{*}$ & 0.311 & $-1.941^{*}$ & 0.308 \\
$\beta_{2}$ & $-2.413^{*}$ & 0.294 & $-2.338^{*}$ & 0.321 \\
$F(2,67)$ & 40.40 & & 26.51 & \\
$R^{2}$ & 0.248 & & 0.191 & \\
Observations & 204 & & 204 & \\
\hline
\end{tabular}

Notes: Standard errors are adjusted for clustering; $*$ significant at the $1 \%$ level; inclusion of control variables such as treatment, sequence,session, age, gender and race are insignificant.

Table 5. Expected voluntary contribution ${ }^{8}$

\begin{tabular}{|c|c|c|c|c|c|}
\hline \multicolumn{3}{|c|}{ Capital } & \multicolumn{3}{|c|}{ Labour } \\
\hline Category & $\begin{array}{c}\text { Expected } \\
\text { Value }=\mathrm{E}(\mathrm{H})\end{array}$ & $\begin{array}{l}\text { Exp. vol. } \\
\text { contribution }\end{array}$ & Category & $\begin{array}{c}\text { Expected } \\
\text { Value }=E(H)\end{array}$ & $\begin{array}{l}\text { Exp. vol. } \\
\text { contribution }\end{array}$ \\
\hline Tax 0 & $\alpha$ & 3.426 & Tax 0 & $\alpha$ & 2.985 \\
\hline Tax 3 & $\alpha+\beta_{2}$ & 1.014 & Tax 4 & $\alpha+\beta_{1}$ & 1.044 \\
\hline Tax 4 & $\alpha+\beta_{1}$ & 0.691 & Tax 6 & $\alpha+\beta_{2}$ & 0.647 \\
\hline
\end{tabular}

Table 6. Percent of groups that met the emission reduction target

\begin{tabular}{ccccc}
\hline $\begin{array}{c}\text { Sequence } 1^{1} \\
(17 \text { groups })\end{array}$ & $\begin{array}{c}\text { Baseline }^{2} \\
(34 \text { groups })\end{array}$ & $\begin{array}{c}\text { Comm. }^{2} \\
(34 \text { groups })\end{array}$ & $\begin{array}{c}\text { Tax36 } \\
(34 \text { groups })\end{array}$ & $\begin{array}{c}\text { Tax44 } \\
(34 \text { groups })\end{array}$ \\
\hline 0.18 & 0.35 & 0.50 & 0.91 & 0.88 \\
\hline Note: ${ }^{1}$ Average across the 4 treatments, ${ }^{2}$ Sequence 2 and 3 &
\end{tabular}

${ }^{8}$ Note that Benzing and Andrews (2004) attribute differences between the expected voluntary contribution and actual reported contributions (in our case the estimates reported in Table 4) to the error term $\epsilon$. 


\section{References}

Anderson, L., Mellor., Milyo, J., 2004, “Inequality, Group Cohesion, and Public Good Provision:

An Experimental Analysis," University of Missouri Economics Working Paper Series.

Andreoni, J., 1993, "An Experimental Test of the Public-Goods Crowding-Out Hypothesis," the American Economic Review, vol. 83(5):1317-1327.

Benzing, C., Andrews, B., 2004, "The Effect of Tax Rates and Uncertainty on Contributory Crowding Out," AEJ, vol. 32(3): 201-215.

Bagnoli, M., Mckee, M., 1991, "Voluntary Contribution Games: Efficient Private Provision of Public Goods,” Economic Inquiry, 29(2), pp. 351-366.

Brekke, K., Johansson-Stenman, O., 2008, "The behavioural economics of climate change," Oxford Review of Economic Policy, 24(2):280 - 297.

Buckley, E., Croson, R., 2006, "Income and Wealth Heterogeneity in the Voluntary Provision of Linear Public Goods,” Journal of Public Economics, 90(5), pp. 935-955.

Chan, K., Mestelman, S., Moir, R., Muller, R., 1996, 'The Voluntary Provision of Public Goods Under Varying Income Distributions,' Canadian Journal of Economics, 29(1), pp. $54-69$.

Chan, K., Mestelman, S., Moir, R., Muller, R., 1999, "Heterogeneity and the Voluntary Provision of Public Goods," Experimental Economics, 2, pp. 5-30. 
Cherry, T., Kroll, S., Shogren, J., 2005, “The impact of endowment heterogeneity and origin on public good contributions: evidence from the lab," Journal of Economic Behavior and Organization, Vol. $57357-365$.

Fehr, E., Fischbacher, E., 2004, "Social norms and human cooperation," Trends in Cognitive Sciences, 8(4):185 - 190 .

Fisher, J., Isaac, R., Schatzberg, J., Walker, J., 1995, “Heterogeneous Demand for Public Goods: Behavior in the Voluntary Contributions Mechanism," Public Choice, 85, pp. 249266.

Gächter, S., Herrmann, B., 2009, "Reciprocity, culture and human cooperation: previous insights and a new cross-cultural experiment," Philosophical Transactions of the Royal Society B, 364:791 - 806 .

Gowdy, J., 2007, "Behavioral Economics and Climate Change Policy," Rensselaer Polytechnic Institute, No. 0701.

Hofmeyr, A., Burns, J., Visser, M., 2007, "Income inequality, reciprocity and public good provision: and experimental analysis," South African Journal of Economics, Vol. 75(3):508 $-520$.

Irwin, T., 2009, "Implications for climate-change policy of research on cooperation in social dilemmas," World Bank Policy Research Working Paper 5006.

Isaac, M., Walker, J., 1988, 'Group Size Effects in Public Goods Provision: The Voluntary Contribution Mechanism,' Quarterly Journal of Economics, 103(1), pp. 179-199. 
Ledyard, J., 1995, "Public Goods: A survey of experimental research," in Kagel, J. and Roth, A.E. (Eds.), Handbook of Experimental Economics. Princeton University Press, Princeton.

National Treasury, 2010, "Budget Review 2010," available online at www.treasury.gov.za.

Palfrey, T., Prisbrey, J., 1997, ‘Anomalous Behavior in Public Goods Experiment: How Much and Why,' The American Economic Review, 87(5), pp. 829-846.

Reuben, E., Riedl, A., 2009, "Enforcement of Contribution Norms in Public Good Games with Heterogenous Populations," CESifo Working Paper, No. 2725.

Winkler, H., Marquard, A., 2009, “Changing development paths: From and energy-intensive to low-carbon economy in South Africa," Climate and Development, 1:47-65. 


\section{$7 \quad$ Appendix}

\section{Appendix A Mann-Whitney test}

\begin{tabular}{lrrr}
\hline $\begin{array}{l}\text { Mann-Whitney test } \\
H_{0}: t_{x}(\text { Session } 1)=t_{x}(\text { Session } 2)\end{array}$ & \\
& Sequence 1 & Sequence 2 & Sequence 3 \\
Treatment 1 & $p=0.354$ & $p=0.975$ & $p=0.131$ \\
Treatment 2 & $p=0.113$ & $p=0.689$ & $p=0.613$ \\
Treatment 3 & $p=0.376$ & $p=0.455$ & $p=0.298$ \\
Treatment 4 & $p=0.830$ & $p=0.375$ & $p=0.160$ \\
\hline
\end{tabular}

Mann-Whitney test

$H_{0}: t_{x}($ Sequence 2$)=t_{x}($ Sequence 3$)$

Baseline

$p=0.1624$

Communication

$p=0.127$

Tax36

$p=0.931$

Tax44

$p=0.939$ 
Appendix B Frequency distributions, by player-type and treatment, Sequence 1 (Baseline)
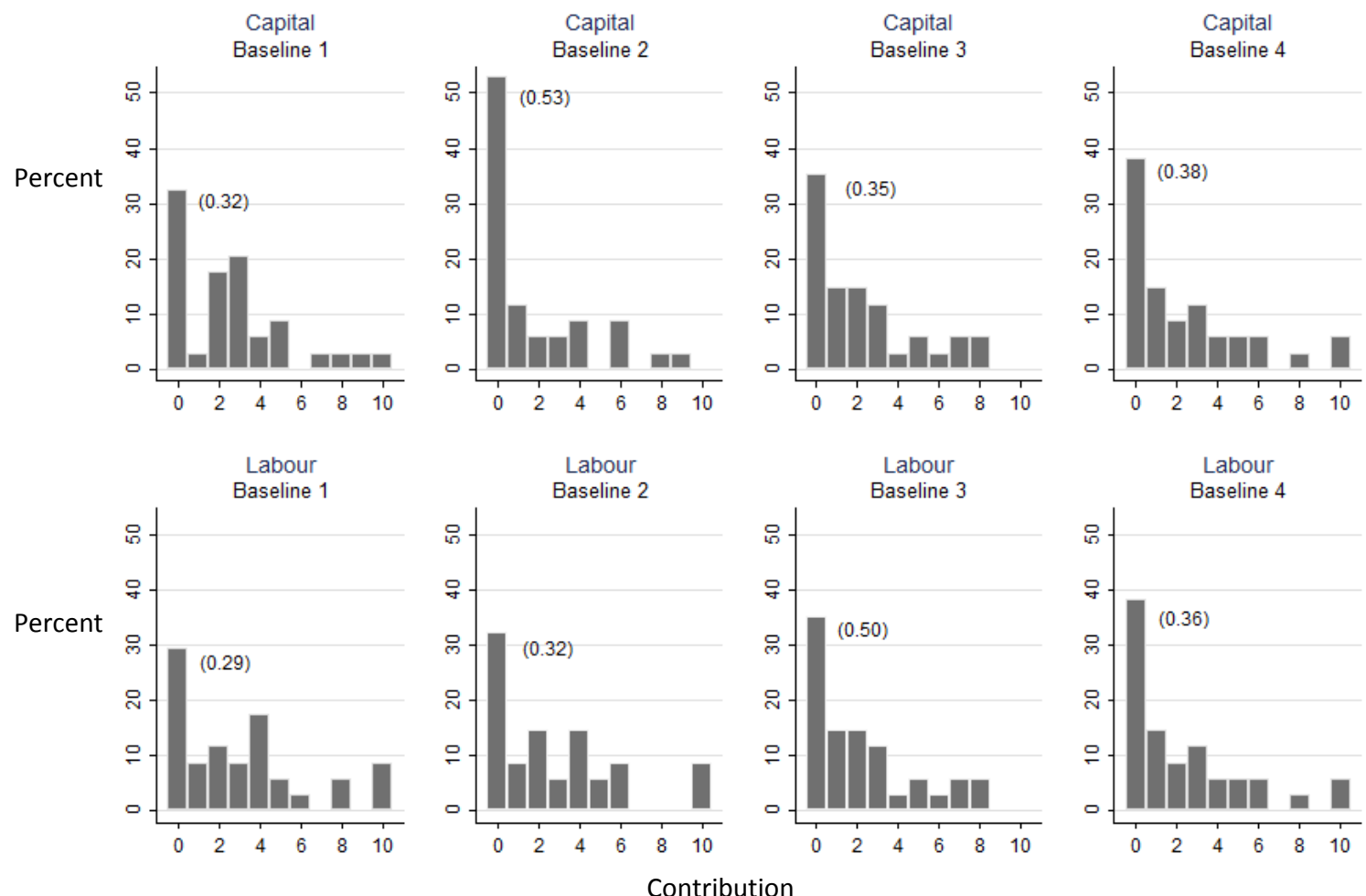

Note: percent free-riding (zero contributions) indicated in parenthesis 
Appendix C Frequency distributions, by player-type and treatment, Sequence 2 and 3
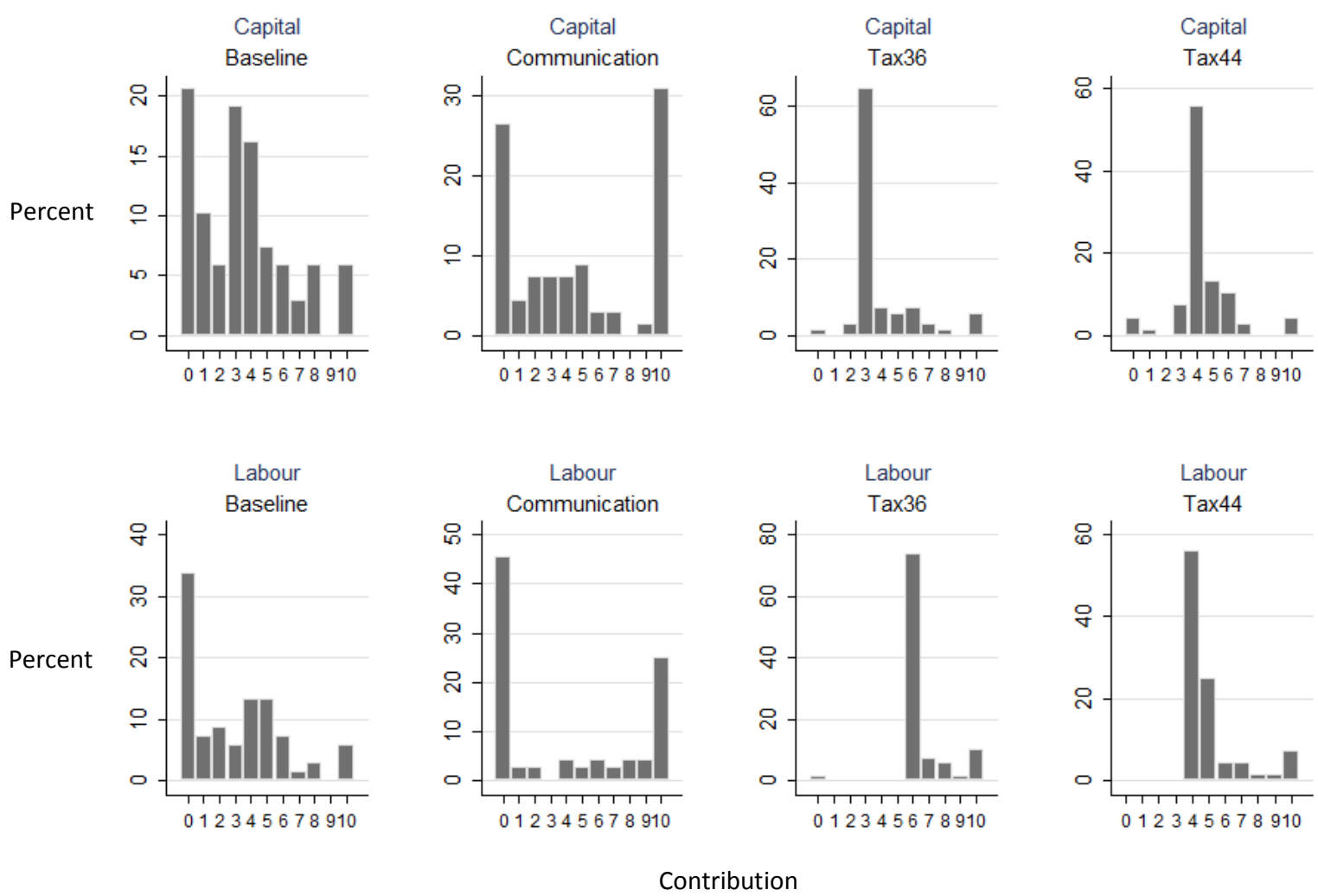

Contribution 